\title{
Urban Teachers' Online Dissent Produces Cultural Resources of Relevance to Teacher Education
}

\author{
Trevor Thomas Stewart ${ }^{1}$ - George L. Boggs ${ }^{2}$
}

(c) Springer Nature B.V. 2018

\begin{abstract}
This paper explores urban teachers' published responses to education reform. These compositions published online are examined as sources of cultural knowledge that are relevant to teacher education. Using sociolinguistic theory and method, the compositions' arguments and rhetorical moves are analyzed to interpret the use of digital compositions to respond to education reform initiatives in the United States. The patterned speech contained in these compositions demonstrates forms of agency important to the pursuit of professional autonomy. This finding has implications for teacher education and raises questions about whether and how cultural resources being developed by urban (and other) teachers through online composition may be ethically appropriated to benefit pre-service and in-service teachers.
\end{abstract}

Keywords Teachers · Dissent $\cdot$ Education reform · Digital composition · Teacher activism

\section{Introduction}

Although teacher dissent and its influence on teacher education is well-established in the literature (Dunn 2015; Peck et al. 2010), online communication tools have shifted the landscape, allowing teachers greater access to public forums in which they can voice dissent and participate in the production of knowledge about teaching and related issues (Boggs and Stewart 2016; Jenkins et al. 2009; Stewart and Boggs 2016). Urban teachers' writing may be especially important as cultural resources supporting alternative views of problems facing urban education (Portnoy and Maloney 2010), and their contributions to online dialogue related to education

Trevor Thomas Stewart

ttstew@vt.edu

1 Virginia Tech School of Education, 309 War Memorial Hall (0313), Blacksburg, VA 24061, USA

2 Florida State University College of Education, Tallahassee, FL, USA 
reform issues may influence pre-service teachers' preconceptions about their own possible roles as teachers in urban settings (Weber 2017).

This paper examines the form and content of online arguments attributed to urban teachers to build upon a growing understanding of conceptual and linguistic resources being produced by teachers experiencing threats to their jobs, the integrity of their schools and communities, and their ability to provide instruction in the current reform climate (Dunn et al. 2017a). As practicing teachers use online platforms to resist changes in their work environments, they are blazing a path for other teachers to follow (Dunn 2015). The influence practicing teachers have on the development of new teachers makes it important to pay attention to these conceptual and linguistic resources as features of teacher education, particularly the development of the ability to participate strategically in media-rich environments.

\section{Problem}

Online social networks and popular media have entrenched a moral panic in which teachers are scapegoats for complex social problems (Goldstein 2014; Labaree 2011). Figure 1 provides one example among many of efforts to frame purported school failure as a simple problem of teacher quality.

Traditional forms of professional teacher advocacy (e.g. teachers' unions) have lost ground in the meantime (Luke 2011) as mass media plays a role in making sense of the worldwide shift toward standardization, privatization, and data-driven accountability (Cody 2014; Ravitch 2013). Teachers, however, are making use of social media platforms to enter the fray themselves and offer alternative perspectives troubling negative depictions of teacher quality (Boggs and Stewart 2016; Stewart and Boggs 2016). Figure 2 provides an example of one urban teacher's effort to rally support for teachers as popular media outlets perpetuate problematic narratives that blame teachers.

Such teacher participation in online debates may serve to resist negative portrayals of teachers in popular media spaces. We have argued previously that such participation represents a shift of the landscape of education reform debates (Stewart and Boggs 2016). This paper explores how teacher participation in online debate produces developmental stimuli available to novice teachers and teacher educators. This production of linguistic resources represents a complicated transmission of

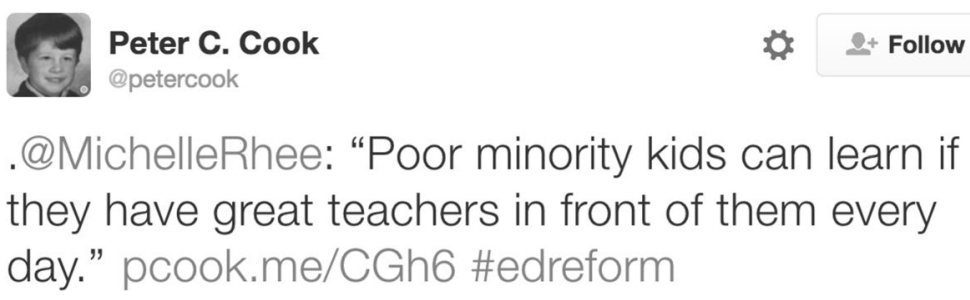

Fig. 1 Tweet interaction points to effort to frame complex educational challenges as simple issues of teacher quality 


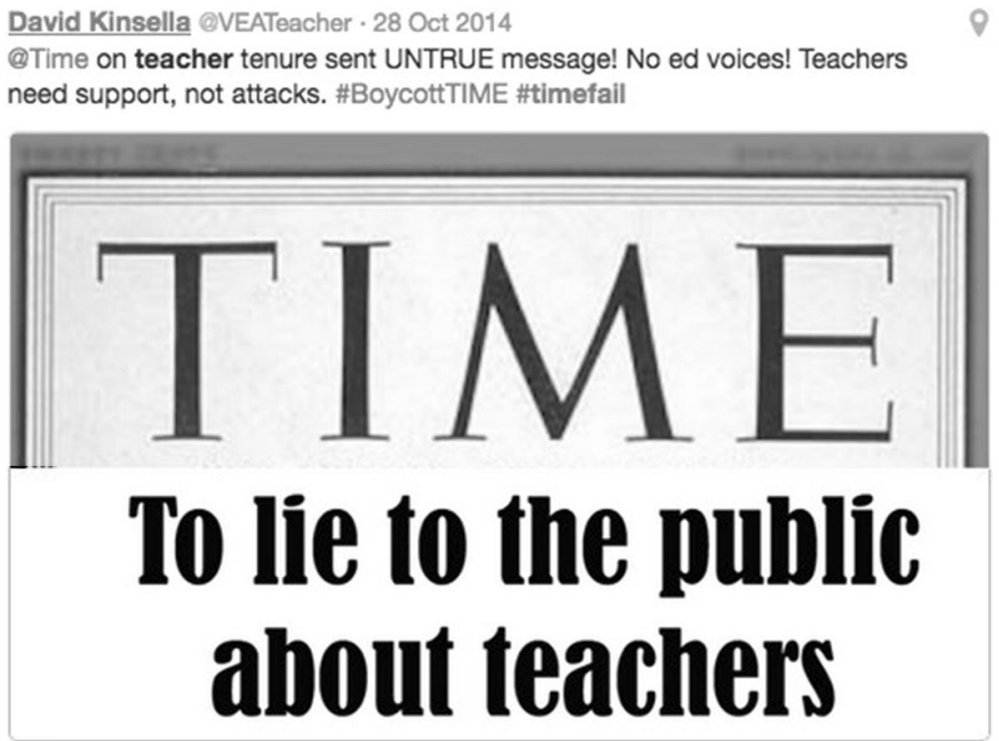

Fig. 2 Urban teacher joins public outcry directed at TIME Magazine cover and articles placing blame on teachers and tenure for failing schools

insider knowledge, which may help other teachers transcend limited roles as they engage in civic action and produce their own messages.

Teacher participation in public dissent presents a conundrum for teacher education. Teachers in urban areas are an important potential source of information about problems facing urban schools. As insiders with direct knowledge of the complex issues that complicate efforts to provide high quality instruction, urban teachers are in a unique position that enables them to offer insight into the realities of their teaching contexts. Yet, active participation in public discussion can be risky for preservice or early career teachers. In many states, dissent of any kind, might become grounds for dismissal. The professional risks associated with teacher dissent and the proliferation of tools for speaking out underline the need for guided participation in acquiring and managing one's professional identity and voice. In spite of the professional hazards associated with public speech (Smagorinsky 2015), many teachers maintain public blogs about their experiences. Blogs, Twitter, and other social media platforms are being used by some teachers to raise objections to prevailing notions of poor teacher quality as an explanation for purported school failure (Supovitz et al. 2015).

\section{Global Education Reform and Teacher Dissent}

Contemporary education reform, part of a global trend of neoliberal reorganization of workforces and workforce development, redefines quality and knowledge in narrow terms of task performance and efficient production of wealth (Gee et al. 1996; 
Weiner 2007). Neoliberal restructuring invokes a free market's ability to guarantee quality by introducing market dynamics, as seen in the cases of for-profit charter school restructuring and the use of standardized test scores to assess teacher quality (Rush and Scherff 2015) that force teachers compete for limited salary resources. This trend intensely affects urban schools as they "come to mirror the problems of urban poverty" and endure intense state and federal scrutiny (Sadovnik and Davidson 2012, p. 29). The trend raises questions about the importance of teachers' speech as they pursue goals other than increased efficiency, such as autonomy (Dierking and Fox 2012; Smagorinsky et al. 2004) and equity (Sleeter 2008).

Our focus on the writing of urban teachers, and the exclusion of other voices, has to do with the destabilization of urban lives through neoliberal education reforms, most notably through school closure and privatized reorganization of 'failing' urban schools (Boggs and Stewart 2016; Lipman 2011). We do not use the term "urban" as a euphemism for issues of race and class (Milner 2012). Instead, we gravitate towards the dissenting voices of those characterizing themselves as urban teachers out of recognition that urban spaces are being actively restructured through current discussions of education reform. Our research addresses a paradox: on one hand is "a rich array of excellence, intellect, and talent among people in urban environments" (Milner 2012, p. 558); on the other hand, the difficulty recruiting and retaining urban teachers and the disproportionate affect that teacher turnover has on minority and beginning teachers" (Dunn 2015, p. 86). New knowledge, relationships, and language may be necessary to manage this paradox.

Critiques of reform produced in and around urban schools are emerging dialogic structures in debates over school improvement (Stewart and Boggs 2016) that may produce valuable resources for redesigning roles for teachers. Still, reform rhetoric often functions to undermine teachers' authority to participate in discussions of school improvement, creating a problem of dialogue for teachers as they enter the profession and adapt to its changes. The legitimacy of teachers' status in discussions of education reform is regularly questioned (Labaree 2004), even by teachers themselves (Stewart 2012). The status of teaching is a site of political struggle, as the work of teachers is evaluated and scrutinized by the media (Edwards 2014; Wall Street Journal 2010) and government institutions (Duncan 2011; Hult and Edström 2016), where "it is commonly assumed that the quality of what teachers do can be improved by people other than teachers themselves" (Bangs and Frost 2012, p. 8). Externalized education improvement strategies that draw on corporate models of organization and neoliberal economic agendas contribute to what has been called de-professionalization of teaching, a situation in which teachers lack a voice or autonomy in educational decision-making (Pritchard and Moore 2016; Race 2002).

In some cases, neoliberal strategies may override, co-opt, or ignore democratic movements (Scott 2013). Top-down reform efforts provide recipes with the asserted capacity to resolve purported challenges facing schools: literacy crises (Graff 2011; Vacca and Alvermann 1998), achievement gaps (Mathis 2005; Valencia 2015), technological divides (Hamel 2010; Maiye and McGrath 2010), and teachers' unions' alleged neglect of teacher quality (Hatch 2015). The complex of purported crises allegedly caused by bad teachers and bad teaching provides varied and convenient means of justifying the reorganization of schooling (Goldstein 2014; Lipman 2011), 
thus compounding the problem of dialogue in which teachers may not know with whom or how to speak beyond their duty regimen.

\section{Dissenting Speech in Participatory Culture}

Pitzer (2015) defines urban teachers' critical talk as "a moment when teachers create a space for other possible constructions of schooling" (p. 6). Pitzer's research presents urban teachers' critical talk collected from interviews, yet collegiality formed through teachers' critical digital compositions may be supporting their efforts to present alternatives to deficit discourses (Smagorinsky 2015). Urban teachers' public dissent is increasingly gaining attention in scholarly literature and in discussions of policy decisions (Cody 2014; Heron-Hruby and Landon-Hays 2014; Neff 2014; Perry 2015). The content of teachers' dissenting messages affects teacher education (Dunn et al. 2017b). Yet some research on teachers' online writing has been critical of unprofessional and apolitical content (Stitzlein and Quinn 2012). Other researchers contend that teachers' online messages should focus on positive classroom outcomes (Smagorinsky 2015). Dunn and her colleagues have studied the emergence of sociolinguistic conventions in teachers' public resignation letters (Dunn et al. 2017a). New media research (Jenkins et al. 2013) supports better understanding of participants' agency as the focal point of creative, collaborative, and connected responses to mass media messages ( Boggs and Stewart 2016; Carpentier 2011).

Our analysis of dissenting compositions focuses on the shared logical and rhetorical characteristics among them, their form and content. Conceptualizing these patterns as cultural resources shared and developed among teachers online, we investigate them as forms of cultural competence (Hymes 1972) that may be vital to the development of teachers' sense of solidarity and efficacy (Dunn et al. 2017b).

\section{Theoretical Framework: Online Speech as Culture}

Our investigation of online dissent assumes a close connection between culture, language, and action. Linguistic habits signal membership in particular communities (Farrah 1998; Hymes 1966). In online composition settings, writing enacts authors' cultural membership through the information they take for granted, their choice of words, and the cosmology of good and evil they invoke. Shared ways of doing language convey important information about a community (Hymes 1964). This process of creating social order through speech results in the production of cultural resources that, in the case of contemporary preservice and practicing teachers, may nurture dissenting views and the ideological becoming of individuals experiencing high-status discourses typical in education reform.

Online writing exemplifies the reduced barriers to publication and circulation of one's speech, in contrast to centrally regulated forms of media production (Jenkins et al. 2009). Democratization of publishing gives teachers new access to a conflictladen cultural activity in which they interweave the backgrounds and former uses of words, phrases, and genres within contemporary cultural norms. It is not possible 
to read a person's mind through their speech acts. Rather, speech acts position language a doing important cultural work to affirm solidarity and engender response.

The following research questions guided this inquiry into how urban teachers' online speech acts may be cultural resources affecting teacher education: What rhetorical patterns were present in urban teachers' critical digital compositions? How did urban teachers' digitally published critical compositions respond to education reform initiatives in the United States?

\section{Method}

We generated data for this inquiry by sampling the rhetorical tools used in certain speech acts, such as blog entries and comments about education reform in urban schools, that occurred online as part of speech events, such as websites with comment sections and blogs. We analyzed teachers' compositions in these speech events to interpret how their strategic communication functions interpersonally. The data set we used to study these speech acts was comprised of online, published expressions of dissent ostensibly composed by urban teachers.

\section{Data Collection}

Prior analysis of teachers' critical talk online has used strategic online searching to generate relevant data (Stitzlein and Quinn 2012). Online compositions-even when published on personal blogs and other online spaces-are important data for understanding the conflicts and ideas surrounding social organization (Hutchinson 2001). Similar to Stitzlein and Quinn's (2012) approach, we collected data using focused search terms (i.e., "blog on teacher evaluations," "urban teacher blog," "why innercity teachers have it harder," and "teacher evaluations aren't fair") that identified published speech acts linking urban teachers to U.S. education reform. Using these search terms, we collected data from 21 different public websites and online discussion spaces to collect statements that appeared to be composed by practicing urban teachers related to current issues in U.S. education reform (e.g., teacher evaluations and high-stakes testing). Table 1 presents the 21 different websites where the data were located, which included individual teacher's blogs, blogs featuring multiple contributors, blog comment sections, activist networks, and popular news outlets, including their discussion spaces.

We compiled 63 compositions attributable to urban teachers, retaining hyperlinks to the compositions. Table 1 contextualizes these speech acts within the speech event in which they occurred (e.g., blog posts and popular media articles with accompanying attached comments). We ascertained the authorship of the speech acts by researching the author's profile, user name, and other clues (e.g., location and employment status) to be as certain as possible that practicing teachers in urban settings crafted each composition. We included anonymous authors' speech acts in the data set when these acts included textual references to employment status and firsthand knowledge of schools and teaching. In the course of analysis, ongoing research 
Table 1 Websites and website categories where data were located

\begin{tabular}{|c|c|}
\hline Website & Type of site \\
\hline The Tri-State Defender & Memphis online news outlet \\
\hline Indiana University South Bend Undergraduate Research Journal & Research paper \\
\hline Education Matters & Jacksonville education blog \\
\hline Facebook Favorite Teacher & Social media meme \\
\hline Washington Post: Answer Sheet & Education blog \\
\hline Diane Ravitch's Blog & Education blog \\
\hline Bay 12 Games Forum: Education reform thread & Discussion board \\
\hline Seattle Schools Community Forum & Education blog \\
\hline Linking and Thinking on Education & Education blog \\
\hline Parenting.com & $\begin{array}{l}\text { New York City teacher's } \\
\text { opinion and comments }\end{array}$ \\
\hline Teaching in the Inner City & Education blog \\
\hline Yahoo Answers & Online discussion board \\
\hline V Bulletin & Online discussion board \\
\hline Time Magazine & Commentary and comments \\
\hline Newsweek & Commentary and comments \\
\hline Education Week Teacher & $\mathrm{B} \log$ \\
\hline An Urban Teacher's Education & $\mathrm{B} \log$ \\
\hline Education Next & Commentary \\
\hline Larry Ferlazzo’s Edu Blog & $\mathrm{B} \log$ \\
\hline Teach.com & Information/Recruiting \\
\hline Bad Ass Teachers Association & $\mathrm{B} \log$ \\
\hline
\end{tabular}

into authorship eliminated eight data points from our inquiry in which speech acts appeared to have been written by teacher educators, former teachers, parents, policymakers, or others who did not appear to be currently practicing teachers in urban schools. We restricted analysis reported in this study to the remaining data set.

\section{Data Analysis}

In our initial analysis, we discussed salient themes and developed shared language through which we organized the data into broad, thematic categories for further analysis (Maxwell 2005). Using these thematic categories, we coded the data to identify trends in the way the collected statements responded to education reform. Themed Argument codes provided a mechanism for organizing the data by thematic arguments in the compositions. We further analyzed the data to examine rhetorical strategies they employed. Table 2 groups the codes according to their thematic content and rhetorical functions.

Table 1 illustrates the diversity of the rhetorical strategies in use and provides the criteria used to assign those codes (Stewart and Boggs 2016). 
Table 2 Coding categories and criteria describe the two categories used to describe data

\begin{tabular}{|c|c|}
\hline Themed arguments codes & Criteria (argument asserts that...) \\
\hline Failed Mandate & $\begin{array}{l}\text { Mismanagement or conflicts of interest have undermined estab- } \\
\text { lished authorities' right to govern policy and practice }\end{array}$ \\
\hline Neoliberal Agenda & $\begin{array}{l}\text { State-sponsored contraction of public services accommodates } \\
\text { private capital development }\end{array}$ \\
\hline Testing & $\begin{array}{l}\text { Inappropriate shifts in curriculum toward test preparation, stand- } \\
\text { ardization, and measurement of students impede teachers' work }\end{array}$ \\
\hline Labor Issues & $\begin{array}{l}\text { Local school and district leadership distracts teachers from doing } \\
\text { their jobs effectively }\end{array}$ \\
\hline Diversity Issues & $\begin{array}{l}\text { Students in urban and other settings face many challenges that } \\
\text { teachers must understand and address; failure to do so results in } \\
\text { ineffective education }\end{array}$ \\
\hline Rhetorical move codes & Criteria \\
\hline Intertextuality & Explicitly includes or references other texts \\
\hline Insider vs. Outsider Status & $\begin{array}{l}\text { Imputes or denies credibility of an argument or speaker based on } \\
\text { their position within or outside urban or other school }\end{array}$ \\
\hline Text Features & $\begin{array}{l}\text { Includes hyperlinks, underlining, boldface type, non-grammatical } \\
\text { punctuation }\end{array}$ \\
\hline Critiquing Narrative & $\begin{array}{l}\text { Explicitly acknowledges, through references to familiar language, } \\
\text { spokespersons, or other metonyms, a popular or established mes- } \\
\text { sage about teachers or education reform }\end{array}$ \\
\hline Personal Anecdote/Indirect Speech & $\begin{array}{l}\text { Elaborates or contests an argument through the use of personal } \\
\text { testimony or by giving voice to purported colleagues' words or } \\
\text { stories }\end{array}$ \\
\hline Historicizing & $\begin{array}{l}\text { Purports to place a situation in historical context, referring explic- } \\
\text { itly to historical events or settings (e.g., segregation and Civil } \\
\text { Rights Movement) }\end{array}$ \\
\hline Rhetorical Question & $\begin{array}{l}\text { Includes a question with an expected answer that aligns with an } \\
\text { argument put forward in the composition }\end{array}$ \\
\hline Gesture to Authority & Cites purportedly authoritative or reliable sources to bolster a claim \\
\hline
\end{tabular}

The Themed Arguments grouping was created from the following themes: Failed Mandate, Neoliberal Agenda, Testing, Labor Issues, and Diversity Issues. This grouping focuses on the use of logical arguments directed at educational reform policies and practices. The Rhetorical Moves grouping identified the effect of formal language choices reflected in the following themes: Intertextuality, Insider vs. Outsider Status, Text Features, Critiquing Narrative, Personal Anecdote/Indirect Speech, Historicizing, Rhetorical Question, and Gesture to Authority. Composition data appeared in more than one compilation when more than one Themed Argument code was applicable. 


\section{Findings}

In this section we describe how teachers' online compositions are strategic responses to Education Reform. Themed Arguments delineated a tendency in teachers' compositions to forward logical arguments concerning educational reform, while the second group, Rhetorical Moves consisted of rhetorical devices and verbal constructions that positioned teachers in relation to their audience, their schools, their work, and education reform messages. We describe our findings related to these to these two groupings below, followed by a consideration of the significance of the emergence of these intertwined, patterned rhetorical resources for teacher education.

\section{Argument Dimensions}

Themed Arguments include speech acts coded as Failed Mandate, Neoliberal Agenda, Testing, Labor Issues, and Diversity Issues. We coded speech acts as Failed Mandate when they challenged the political high ground from which education reform emanated. "The culprit is the American education system PERIOD," reads one excerpt from a teacher's online post, "It is a national tragedy that $A L L$ schools are not equal; equal in terms of classes offered, rigor, quality of facilities, books, teachers and support staff." Failed Mandate compositions defend the efforts of teachers against education reform messages critiquing teachers by presenting the sources of education reform initiatives as untrustworthy. Speech acts coded as Neoliberal Agenda associated education reform initiatives with the social, economic, and political philosophy of neoliberalism. The composition, "So what we have is a political and corporate power structure using federal dollars to gain access and control over our black and brown children from the time they enter school until they leave," illustrates how Neoliberal Agenda arguments recast educational reform as the state-supported conversion of public education to a market economy. These compositions presented education reform and reformers as henchman of an unsavory public policy that favors big business over vulnerable populations.

Urban teachers' compositions coded as Testing challenged the mechanics of educational reform. These speech acts attributed significant harm to the fulcrum of contemporary education reform: high-stakes testing. They targeted test preparation as a drag on the curriculum, presented research showing that tests disproportionately penalize certain groups, and defended their pupils whom they saw as suffering under the pressure to perform. The compositions presented Labor Issues as a confounding counterargument to narratives framing teachers in classrooms as the weak link in U.S. education. These speech acts argue that following orders and implementing new curricula threaten teacher professional responsibility and agency. Compositions coded Diversity Issues deflected criticism toward schools by pointing to the diverse populations teachers in urban settings often serve. These compositions countered the reform message demanding a standardized approach to school improvement.

Rhetorical Moves identified in the compositions served a variety of complementary rhetorical purposes. They represent important rhetorical strategies setting up 
certain kinds of connections with potential audiences and directing attention toward particular language and argumentation.

\section{Interpersonal Dimensions of the Speech Acts}

Rhetorical Moves supported attempts to connect with readers in ways that assist interpersonal efforts to trouble reform rhetoric disparaging teachers. These moves addressed two audiences in particular: the general public (including fellow teachers, parents, and journalists) as a set of potential allies, and powerful agents of reform as a set of established adversaries. The data compiled with the Rhetorical Moves group afforded the representation of teachers as credible and capable observers of U.S. education, and they supported the production of divergent meanings from existing policy and popular messages about reform. In the following excerpt, crafted by a teacher who said he or she had been teaching in the Bronx (NY) since 1996, Insider vs. Outsider Status and Text Features functioned to advance an argument questioning the authority and competence of reformers: "Now, I'm tired of Bloomberg, Black, Gates, Rhee, Whitney Tilson, etc., who think they know all when they know nothing."

Rhetorical Moves included features of urban teachers' speech acts directed at immediate audiences hypothetically present in the speech event and at the putative sources of misinformation. Illustrating the complex interpersonal work represented through the Rhetorical Moves, the excerpt below draws upon Text Features (i.e., capitalization and hyperlinks) and Intertext (i.e., referenced materials and message) to bolster arguments coded as Diversity Issues:

Taken as a whole, standardized test scores do NOT demonstrate mastery of skills. They show a students' parental income [hyperlinked to related to Washington Post blog]. In general, poor kids score badly and rich kids score well.... If you really wanted to improve the US education system, you'd address this glaring problem.

Here both interpersonal aspects are displayed. A popular audience is projected through the text features that direct hypothetical readers' attention. The composition also references powerful reform discourses, and thus a second interpersonal plane. Through compiling, summarizing, mocking, and contesting reform narratives, the composition presents an alternative and authoritative reading of the existing words of those in positions of power.

Interpersonal dimensions occurring in teachers' speech projected a living dialogue with existing texts and speakers (Bakhtin 1981). For example, a first-year teacher wrote, "I think it's naive to think that these schools don't have good teachers who would be way more effective in a better environment." Another teacher critiqued a similar narrative, contesting notions of teacher quality by saying, "No matter what measure of 'quality' you look at, poor and minority students - and not just those in inner-city schools-are much less likely to be assigned betterqualified and more-effective teachers." Both teachers participated in a living 
dialogue as they critiqued notions of poor teacher quality, which functions as a key component of neoliberal reform narratives (Pitzer 2015).

Diversity Issues grouped many passionate attempts to connect with others about the right way to see persistent problems. For example, one composition tersely stated, "If you claim you're interested in Education Reform but you're not addressing child poverty, then you're just blowing smoke. Poverty is the biggest problem facing public education, and almost no one is talking about it." Another composition appealed to readers' sense of fairness and concern for child welfare by saying: "Poor and low-income children are unfairly punished for their socioeconomic circumstances that they have nothing to do with; likewise, wealthier students are rewarded for their socioeconomic circumstances, of which they have nothing to do with." These excerpts exhibit the potential for language to be loaded with meaning that draws upon important cultural values. This persuasive work was supported in numerous ways by interpersonal elements of additional rhetorical strategies.

\section{Rhetorical Repertoire}

Rhetorical patterns in teachers' compositions suggested the existence of a set of communicative resources privileged among speakers protesting education reform as urban educators. Rhetorical patterns provide insight into shared cultural values of teachers who are speaking out publicly. Themed Arguments (Table 2) provide a survey of public intellectual positions being developed by and available to teachers. These logical-rhetorical themes are ubiquitous in research literature critical of the effects of neoliberal reform on teacher well-being (Acton and Glasgow 2015), privatization (Patrick 2013), and accountability (Apple 2007). Teachers' production of these logical-rhetorical resources is significant. Compositions published by urban teachers are logically and rhetorically entwined with the work of teaching. Moreover, these compositions extend the work of teaching into the public sphere. Rhetorical Moves (Table 2) reinforce the distinctive rhetorical positions that urban teachers' compositions employ. These rhetorical moves are adapted to online social-rhetorical settings. They include familiar rhetorical devices, such as rhetorical questions and text features, as well as verbal moves that position teacher protagonists as credible sources (e.g., Insider vs. Outsider Status).

Many compositions that we collected employed multiple Themed Arguments and more than one Rhetorical Move, a symptom of the fluid linguistic repertoires shared by speakers. These patterned rhetorical resources likely play multiple roles within the complex cultural setting of online communication platforms. Two roles are particularly important to the present inquiry. First, patterns in speakers' rhetoric point to cultural norms that may be emerging in a community. Second, because these norms form part of speakers' efforts to assert themselves in potentially contentious online communication environments, the patterns observed as features of online writers' repertoires can be understood as cultural resources useful for engaging in interactions with audiences. 


\section{Authorial Patterns Supported by a Speech Community}

We associate displays of communicative competence in a particular setting as evidence of authorial agency with respect to a fluid set of rhetorical resources. The excerpts from teachers' compositions discussed in this section illustrate respective speakers' "bid[s] for a unique creative contribution fully or partially recognized by a relevant community" (Matusov 2011, p. 24). Authorship denotes the social and conceptual capacity to function as a peer with emerging authority to contribute within a community of practice (Lave and Wenger 1991).

In the composition below, the speaker exhibits agency as a legitimate contributor to public debate by contextualizing current issues against a historical backdrop:

Brown vs. Board of Education forced them to do right by black kids in the 60 s, but we Memphians must force them to do the right thing now. We cannot leave them to their own devices and expect them to do the right thing.

The speech act above challenges the right of institutionalized power in a state where teachers do not have core privileges associated with union representation. Such dissenting speech points to the close relationship between authorial agency and leadership in which teachers' compositions are politically significant acts. The composition arranges dialogic threads attached to "black kids," "the 60's," and "do right" to connect past success to current opportunity. The composition redefines contemporary education reform together with the Brown decision as the work of the people. The personal status upon which authorial agency depends is evident in the composition's presentation of the "We Memphians" as acting in parallel as the United States Supreme Court to force policymakers to act justly.

While the former composition placed contemporary institutional dereliction of duty in historical context, the speech act below uses such failure to author a proverb or aphorism referencing inequitable practices:

Where there is money, there is education. Where there isn't money, there is excessive testing, lack of curricular options, and struggle. There is the struggle to give students the tools they need to fight their way through a system that is designed to hold them back from the moment they take their first breath, from the moment they try to write their first paragraph.

This composition makes no bones about its speaker's disdain for "a system" that defiles her life's work by demanding educational practices that she sees as inhibiting learning and social justice initiatives. The composition not so subtly suggests that those in power have not safeguarded the interest of the public. Words like "force" and "fight" function as calls to contentious action.

Rhetorical Moves such as Personal Anecdote/Indirect Speech and Insider vs. Outsider Status fuse the credibility of the speaker to the profession and discredit the absurdity and incongruity of contemporary data-driven reform:

Governments and administration are all about data, at every level. From an outside perspective, this seems like an obvious thing that should be required. A good teacher realizes that data is crucial for their profession as well. Their are certainly 
2 different approaches to this. Just as one example, in my state, there are now certain criteria to which teachers are evaluated on. One is the amount of 'growth' that a student has from the beginning of the year to the end. A fellow teacher had a student on an IEP (individual education plan...basically, a kid that needs help in one way or another to get through school) score insanely high on the beginning of the year test. Like high school level. Why? We can all realize that you can get lucky clicking random buttons. The end of the year tests were just administered, and that same student 'lost 7 YEARS' of knowledge. That's it. No re-do. It is now forever ingrained in that teachers file that they were responsible for erasing 7 YEARS of knowledge from a student, which in reality is simply because the student scored luckily on a poorly designed multiple choice test.

The alarming story contained in this composition demonstrates how Rhetorical Moves can augment arguments that strategically offer alternative explanations for criticism leveled at teachers.

As the compositions used logical arguments to critique reform rhetoric and present counter-narratives, many also drew upon support from messages published presumably by peers and mentors. For example, the blog post below, coded as Labor Issues, Rhetorical Question, and Text Features includes hyperlinks referencing other teacher-activist writings to support its claims:

New teacher evaluation systems in New Haven, DC, Baltimore, NYC and plenty of other places across the country will make it exceedingly difficult for anyone in an urban school to keep a job for longer than a few years. What better way to get rid of tenure than to never grant it to anyone in the first place? I, for example, might soon be required to move 85 percent [hyperlinked to an earlier post within author's blog] of my students to grade-level proficiency despite many of them being unable to read or write a paragraph in English.

One of the hyperlinks connected to yet another post on the blog in which the author explains that he had reached out directly to two well-known bloggers and teacher advocates, Valerie Strauss and Rick Hess, for help making sense of reformers' claims.

Argumentative and rhetorical resources that afford dissenting positions are cultural products occurring in multicultural, contentious settings where the significance of people's voices in a conversation is virtually always up for review. Urban teachers' compositions employ the words of others in a variety of strategic arguments and rhetorical moves. The struggles encoded textually are interpersonal, with teachers projecting solidarity, despair, wisdom, and willingness to resist in the midst of tremendous conflict. The difficult and often risky work involves teachers taking up authorial positions on reforms intended to marginalize them.

\section{Discussion}

The presence and patterned nature of speech in urban teachers' online compositions contesting contemporary education reform represent cultural resources relevant to teacher education. Prior research exploring teachers' online dissent noted a tendency 
for teachers to express their concerns apolitically and to withhold their professional knowledge and status to in their writing (Stitzlein and Quinn 2012). Our analysis of the content of urban teachers' online writing points to the self-consciously political stances that they are producing. Further, the rhetorical tools employed in these compositions leveraged teachers' professional knowledge, insider status, and commitment to their work.

As online activism is increasingly recognized as matter of concern for teacher education (Dunn et al. 2017b; Heron-Hruby and Landon-Hays 2014), important questions arise about how traditional organs of teacher education, such as colleges of education and professional development, may learn from the cultural legacy rapidly developing online. These cultural resources shape how teachers "envision a way forward for the profession" (Dunn et al. 2017b, p. 288), especially given the staffing issues in urban schools (Sadovnik and Davidson 2012). Future urban teachers are likely to draw upon resources produced outside of the local school environment by their families, the community, and more experienced peers who may not be in the building. The cultural resources produced by teachers online may prove to be critical assets for teacher educators seeking point their students to networks of support.

Cultural resources produced by practicing teachers in online settings are valuable because they use diversity as a construct to question standardization. They place powerful reform discourses against broader educational, political, and economic backdrops. They fuse teacher credibility as insiders with rejection of unrealistic policies foisted upon their schools. Taking a variety of forms, urban teachers' compositions deny the agency of standardized testing, question the authority of policymakers, and assert authority based on experience, professional knowledge, and relationships with individuals and groups affected by policy.

The cultural resources we described consist of particular modes of action that could inspire "fear of administrative reprisal" (Smagorinsky 2015, p. 92). The tense relationship between the production and use of these cultural resources may be seen in one urban teacher's blog description:

This blog is my space for venting, for tooting my own horn unashamedly, for crying over my failures, and for publicly saying things that I do not dare say at my school because, quite frankly, the stuff that I will say will piss folks off no end. Not a positive work environment.

We frame such cultural resources as desirable as they project identities for beginning teachers or others who see their professional capacities abused with impunity. Such resources are fraught with risk, however, because they "belong" to individual members of the profession in different ways. Figuring out how dissenting views belong to and might support new professionals is part of the work of teacher education. Effective teacher preparation includes guided engagement in a process of learning to learn about the profession from a wide variety of sources. As Barnes and Smagorinsky (2016) have noted, teacher education can be improved by embracing a variety of sources of knowledge that can contribute to developing novice teachers' conceptions of what it means to be an effective teacher. This process may involve pre-service teachers learning how to weigh the competing voices seeking to influence, reward, or punish them for their actions in and out of the classroom. 


\section{Resources for Teacher Education}

We encourage teacher educators to use what they already know about practicing teachers' production of useful resources for the benefit of those learning to teach. Teachers' participation in online debates over education reform may be analogous to more familiar challenges, such as using another teacher's lesson plans as a model, navigating the dynamics of sharing a classroom with a more experienced mentor teacher, or learning to use existing instructional resources (e.g. textbooks) that might not offer the flexibility to make ready connections to the lives of students. Creating opportunities for preserve teachers to engage in dialogue with practicing teachers' online compositions represents an opportunity to prepare novice teachers to participate in the shifting landscape of education reform discourse.

We have begun to experiment in our own teacher education classrooms with role-plays that we hope can heighten preservice teachers' awareness of and build initial experiences with the cultural resources practicing teachers produce as they respond to reform imperatives. In these class sessions, small-group 'school faculty teams' were presented with examples of the kinds of demands they might receive a from the state or district that would challenge their autonomy. The idea has been to cultivate a willingness to adopt arguments that constructively offer meaningful solutions. In one recent scenario their content area priorities were intentionally ignored as they were asked to produce a 'school-wide comprehensive dyslexia intervention plan,' prompting preservice teachers to search for arguments and rhetorical moves that could constructively manage this imposition.

Cultural resources being created among urban teachers dissenting online manifest powerful modes of professional action that may attract, inspire, mislead, frustrate, distract, or confuse pre-service and early career teachers. However, teacher educators can draw upon their existing practices for supporting preservice teachers as they learn participate in productive conversations. Teacher educators already provide guidance for novice teachers as they discover lesson plans online, in a curriculum library, or in a highly regimented pacing guide by supporting the development of critical readers who effectively draw upon cultural resources produced by others as they learn to craft their own instructional materials.

Just as existing materials require strategic adaptation in order to effectively support learning in specific contexts, teachers' online dissent invites thoughtful interpretation that takes into account pre-service teachers' experience, identifies, and concerns. Strategic adaptation of existing materials creates a balance of agency, which transforms existing materials to serve particular purposes at particular times. Teacher educators can help pre-service teachers learn to participate carefully in these networks through productive conversations with other professionals who have direct knowledge of their specific situations. Pre-service teachers need safe opportunities to interact with these resources, and perhaps even play with them and try them on. 


\section{Respecting Urban Teachers' Writing and Pre-Service Teachers' Learning}

Social media platforms afford a variety of ways for individuals to speak and be heard, so teacher education may adopt practices that strategically support practicing teachers' changing roles in ways that also encourage reflective consideration of dissent among pre-service teachers (Stitzlein 2015). Pre-service teachers' journeys to their own classrooms are complex. Helping them navigate the use of cultural resources represents a key element of this evolving journey. Teachers' dissenting compositions should not be appropriated uncritically. The respect and ethical awareness necessary to learn from teachers' critical digital compositions is analogous to the dispositions required for working with cooperating teachers and administrators across significant differences in status and experience. Learning from the cultural resources beginning teachers are likely to encounter online is a worthy goal for teacher education.

\section{References}

Acton, R., \& Glasgow, P. (2015). Teacher wellbeing in neoliberal contexts: A review of the literature. Australian Journal of Teacher Education, 40(8), 98-114.

Apple, M. W. (2007). Educations, markets, and an audit culture. International Journal of Educational Policy, 1(1), 4-19.

Bakhtin, M. M. (1981). Discourse in the novel. (C. Emerson \& M. Holquist, Trans.). In M. Holquist (Ed.), The dialogic imagination: Four essays by M. M. Bakhtin (pp. 259-422). Austin, TX: University of Texas Press.

Bangs, J., \& Frost, D. (2012). Teacher self-efficacy, voice, and leadership: Towards a policy framework for education international. Brussels: Educational International.

Barnes, M. E., \& Smagorinsky, P. (2016). What English/language arts teacher candidates learn during coursework and practica: A study of three teacher education programs. Journal of Teacher Education, 67(4), 338-355.

Boggs, G. L., \& Stewart, T. T. (2016). Critical digital literacies, education reform, and urban teachers' right to the city. The SoJo Journal: Educational Foundations and Social Justice Education, 1(2), 63-79.

Carpentier, N. (2011). New configurations of the audience? The challenges of user-generated content for audience theory and media participation. In V. Nightingale (Ed.), The handbook of media audiences (pp. 190-212). Malden: Wiley-Blackwell.

Cody, A. (2014). The educator and the oligarch: A teacher challenges. The Gates Foundation. New York, NY: Garn Press.

Dierking, R. C., \& Fox, R. F. (2012). Changing the way I teach: Building teacher knowledge, confidence, and autonomy. Journal of Teacher Education, 64(2), 129-144.

Duncan, A. (2011). An open letter from Arne Duncan to America's teachers in honor of Teacher Appreciation Week. Education Week, May 2, 2011. Retrieved from http://www.edweek.org/ew/artic les/2011/05/02/30duncan.h30.html.

Dunn, A. H. (2015). The courage to leave: Wrestling with the decision to leave teaching in uncertain times. The Urban Review, 47(1), 84-103.

Dunn, A. H., Deroo, M., \& VanDerHeide, J. (2017a). With regret: The genre of teachers' public resignation letters. Linguistics and Education, 38, 33-43.

Dunn, A. H., Farver, S., Guenther, A., \& Wexler, L. J. (2017b). Activism through attrition?: An exploration of viral resignation letters and the teachers who wrote them. Teaching and Teacher Education, 64, 280-290.

Edwards, H. S. (2014). The war on teacher tenure. Time. Retrieved April 11, 2017 from http://time. com/3533556/the-war-on-teacher-tenure. 
Farrah, I. (1998). The ethnography of communication. In N. H. Hornberger \& P. Courson (Eds.), Encyclopedia of language and education: Volume 8: Research methods in language and education (pp. 125-127). Dordrecht, ND: Kluwer.

Gee, J. P., Hull, G. A., \& Lankshear, C. (1996). The new work order: Behind the language of the new capitalism. Boulder, CO: Westview Press.

Goldstein, D. (2014). The teacher wars: A history of America's most embattled profession. New York, NY: Doubleday.

Graff, H. J. (2011). Literacy myths, legacies, and lessons: New studies on literacy. New Brunswick, NJ: Transaction.

Hamel, J. Y. (2010). ICT4D and the human development and capabilities approach: The potentials of information and communication technology. Human Development Research Paper 2010/37, UNDP. Retrieved April 11, 2017 from http://hdr.undp.org/sites/default/files/hdrp_2010_37.pdf.

Hatch, J. A. (2015). Reclaiming the teaching profession: Transforming the dialogue on public education. Lanham, MD: Rowman \& Littlefield.

Heron-Hruby, A., \& Landon-Hays, M. (Eds.). (2014). Digital networking for school reform: The online grassroots efforts of parent and teacher advocates. New York, NY: Palgrave-Pivot.

Hult, A., \& Edström, C. (2016). Teacher ambivalence towards school evaluation: promoting and ruining teacher professionalism. Education Inquiry, 7(3), 305-325.

Hutchinson, R. (2001). Dangerous liaisons? Ethical considerations in conducting online sociological research. Paper presented at the TASA 2001 conference of the Australian Sociological Association, 13-15 December, University of Sydney, Sydney, Australia.

Hymes, D. H. (1964). Introduction: Toward ethnographies of communication. In J. J. Gumperz \& D. Hymes (Eds.), The ethnography of communication (pp. 1-34). Washington, DC: American Anthropological Association.

Hymes, D. H. (1966). Two types of linguistic relativity. In W. Bright (Ed.), Sociolinguistics. The Hague, ND: Mouton.

Hymes, D. H. (1972). On communicative competence. In J. B. Pride \& J. Holmes (Eds.), Sociolinguistics. Selected readings (pp. 269-293). Harmondsworth, UK: Penguin.

Jenkins, H., Ford, S., \& Green, J. (2013). Spreadable media: Creating value and meaning in a networked culture. New York, NY: NYU press.

Jenkins, H., Purushotma, R., Weigel, M., Clinton, K., \& Robison, A. J. (2009). Confronting the challenges of participatory culture: Media education for the 21st century. Cambridge, MA: Mit Press.

Labaree, D. F. (2004). The trouble with ed schools. New Haven: Yale University Press.

Labaree, D. F. (2011). Targeting teachers. Dissent, 58(3), 9-14.

Lave, J., \& Wenger, E. (1991). Situated learning: Legitimate peripheral participation. New York, NY: Cambridge University Press.

Lipman, P. (2011). The new political economy of urban education: Neoliberalism, race, and the Right to the City. New York, NY: Routledge.

Luke, A. (2011). Generalizing across borders: Policy and the limits of educational science. Educational Researcher, 40(8), 367-377.

Maiye, A., \& McGrath, K. (2010). ICTs and sustainable development: A capability perspective. In AMCIS 2010 Proceedings, 541. Retrieved April 11, 2017 from http://aisel.aisnet.org/amcis2010/541.

Mathis, W. J. (2005). Bridging the achievement gap: A bridge too far? The Phi Delta Kappan, 86(8), $590-593$.

Matusov, E. (2011). Authorial teaching and learning. In E. J. White \& M. Peters (Eds.), Bakhtinian pedagogy opportunities and challenges for research, policy, and practice in education across the globe (pp. 21-46). New York, NY: Peterlang.

Maxwell, J. A. (2005). Qualitative research design: An interactive approach (2nd ed.). Thousand Oaks, CA: Sage.

Milner, H. R., IV. (2012). What is urban education? Urban Education, 47(3), 556-561.

Neff, B. (2014). 'Bad ass teachers' go BATs in Washington protest. The Daily Caller News Foundation [Online newspaper]. Retrieved April 11, 2017 from http://dailycaller.com/2014/07/28/badass-teach ers-go-bats-in-washington-protest/.

Patrick, F. (2013). Neoliberalism, the knowledge economy, and the learner: Challenging the inevitability of the commodified self as an outcome of education. ISRN Education, 2013, 1-8.

Peck, C., Gallucci, C., \& Sloan, T. (2010). Negotiating implementation of high-stakes performance assessment policies in teacher education: From compliance to inquiry. Journal of Teacher Education, 61(5), 451-463. 
Perry, M. (2015). Common Core critics protest Jeb Bush speech in Tampa. Florida Politics [Online newspaper]. Retrieved April 11, 2017 from: http://floridapolitics.com/archives/185298-common-corecritics-protest-jeb-bush-speech-in-tampa.

Pitzer, H. (2015). Urban teachers engaging in critical talk: Navigating deficit discourse and neoliberal logics. Journal of Educational Controversy, 9(1), 1-16.

Portnoy \& Maloney. (2010). Retrieved June 23, 2017 from https://www.nwp.org/cs/public/print/resou rce/3239.

Pritchard, C., \& Moore, J. E. (2016). Variables influencing teacher autonomy, administration coordination, and collaboration. Journal of Educational Administration, 54(1), 58-74.

Race, R. (2002). Teacher professionalism or deprofessionalisation? The consequences of school-based management on domestic and international contexts. British Educational Research Journal, 28, 459-463. https://doi.org/10.1080/01411920220137494.

Ravitch, D. (2013). Reign of error: The hoax of the privatization movement and the danger to America's public schools. New York, NY: Alfred A Knopf.

Rush, L. S., \& Scherff, L. (2015). Value-added models and why we should all be worried. English Education, 47(3), 195-203.

Sadovnik, A. R., \& Davidson, T. B. (2012). The sociology of urban education. In K. S. Gallagher (Ed.), Urban education: A model for leadership and policy (pp. 29-47). New York, NY: Routledge.

Scott, J. (2013). Educational movements, not market moments. In M. B. Katz \& M. Rose (Eds.), Public education under siege (pp. 84-90). Philadelphia, PA: University of Pennsylvania Press.

Sleeter, C. (2008). Equity, democracy, and neoliberal assault on teacher education. Teaching and Teacher Education, 24(8), 1947-1957.

Smagorinsky, P. (2015). Speaking out in the public sphere: Why, what, where, and how teachers can enter the fray. English Journal, 104(3), 91-96.

Smagorinsky, P., Cook, L. S., Moore, C., Jackson, A. Y., \& Fry, P. G. (2004). Tensions in learning to teach: Accommodation and the development of a teaching identity. Journal of Teacher Education, 55(1), 8-24.

Stewart, T. T. (2012). English teachers, administrators, and dialogue: Transcending the asymmetry of power in the discourse of educational policy. English Education, 44(4), 375-393.

Stewart, T. T., \& Boggs, G. L. (2016). Emerging dialogic structures in education reform: An analysis of urban teachers' online compositions. Dialogic Pedagogy: An International Online Journal, 4, $142-161$.

Stitzlein, S. M. (2015). Teaching for dissent: Citizenship education and political activism. New York, NY: Routledge.

Stitzlein, S. M., \& Quinn, S. (2012). What can we learn from teacher dissent online? The Educational Forum, 76(2), 190-200.

Supovitz, J., Daly, A., \& Del Fresno, M. (2015). \#commoncore Project. Retrieved April 11, 2017 from http://www.hashtagcommoncore.com.

Vacca, R. T., \& Alvermann, D. E. (1998). The crisis in adolescent literacy: Is it real or imagined? National Association of Secondary School Principals Bulletin, 82(600), 4-9.

Valencia, R. R. (2015). Students of color and the achievement gap: Systemic challenges, systemic transformations. New York, NY: Routledge.

Wall Street Journal (2010). Unions v. race to the top: States are waiting for Arne Duncan. The Wall Street Journal, January 7, 2010. Retrieved from http://www.wsj.com/articles/SB100014240527487034 83604574630423614312770.

Weber, S. (2017). The impact of service learning on pre-service teachers preconceptions of urban teacher education. Journal of Inquiry \& Action in Education, 8(2), 21-33.

Weiner, L. (2007). A lethal threat to U. S. teacher education. Journal of Teacher Education, 58(4), 274-286. 